\title{
SELECTED ASPECTS RELATED TO PREPARATION OF A FATIGUE TEST PLAN OF A METALLIC AIRFRAME
}

\author{
Józef Brzęczek \\ Henryk Gruszecki \\ Leszek Pieróg \\ Janusz Pietruszka
}

\author{
Polskie Zakłady Lotnicze Sp. z o.o., ul. Wojska Polskiego 3, 39-300 Mielec \\ j_brzeczek@pzlmielec.com.pl, h_gruszecki@pzlmielec.com.pl, \\ 1_pierog@pzlmielec.com.pl,j_pietruszka@pzlmielec.com.pl
}

\begin{abstract}
Service life of the PZL M28 is computed based on the results of the full-scale fatigue tests of the structure [1]. As the PZL M28 is a commuter category airplane according to the 14 CFR Part 23 and CS-23 regulations, the test objects were: (1) wing and wing load carry-through structure, (2) empennage and attached fuselage structure. Additionally, there were fatigue tests carried out for the landing gear and other selected elements including control system elements. The aircraft load carry-through structure is metallic and the cabin is unpressurized. The fatigue tests were conducted stage-by-stage. As tests progressed, it was possible to extend the aircraft target service life, applying the safe-life philosophy with reference to the primary components of the load carrythrough structure.

The article brings into attention selected issues related to the fatigue tests plan preparation, with focus on wing and wing load carry-through structure test.
\end{abstract}

Keywords: metallic airframe structure, full scale fatigue tests

\section{MODEL OF AIRPLANE OPERATION}

The first and very important step in determining an aircraft's service life is to establish its operation model. The goal is to establish the basic parameters of airplane operation affecting the airframe service life and to enable the proper selection of load cases for the purpose of conducting fatigue analyses and fatigue tests.

A typical flight profile, i.e. basic flight parameters, of the PZL M28 05 in one-hour flight is shown in Fig. 1 [2]. The assumption of the average flight time of one hour was confirmed by the airplane operators, and, statistical distribution of the flight duration on a sample airplane was performed - see Fig. 2. As the airplane has the short take-off and landing (STOL) characteristics and is approved for operation from unpaved airstrips, it was assumed that:

- $50 \%$ of takeoff-landings are performed from paved airstrips,

- $50 \%$ of takeoff-landings are performed from unpaved airstrips. 


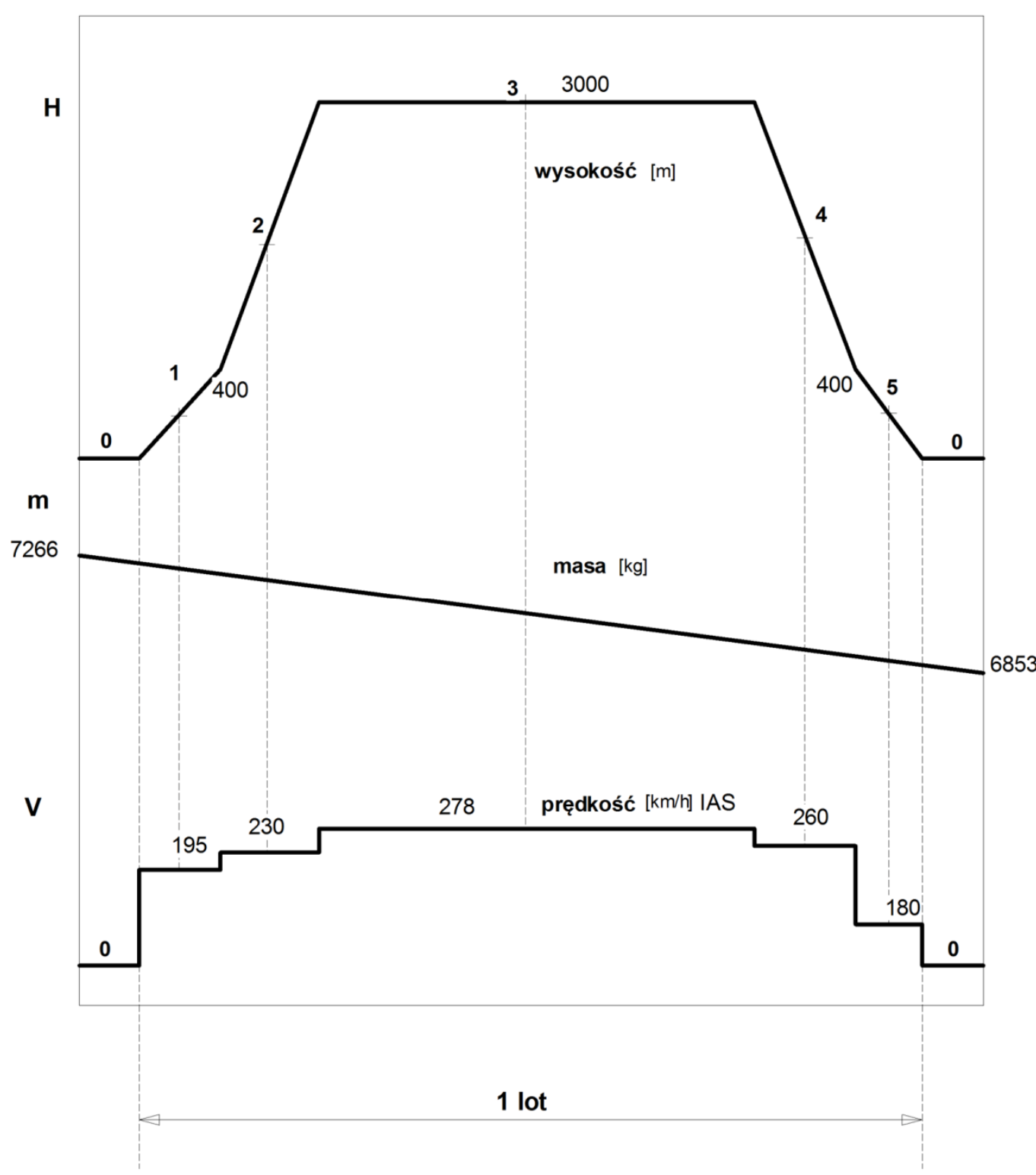

Fig. 1. A typical flight profile of the PZL M28 05. Airspeed, flight altitude and aircraft weight are shown. Assumed flight duration is one hour. Mission consists of:

0 - taxiing, ground roll before take-off and after landing,

1 - take-off and initial climb to 400m above airfield altitude,

2 - climb to cruise altitude,

3 - cruise,

4 - descend to 400m above airfield altitude,

5 - go-around and landing.

It corresponds to flights from the base airfield to the operational one and back, given that refueling is performed every second flight (according to the information received from an operator). During short flights a controlled space is not entered, that is FL095 (9500 ft.) is not exceeded. Longer flights are performed in the controlled space, taking into account the limitations resulting from non-pressurized fuselage. 


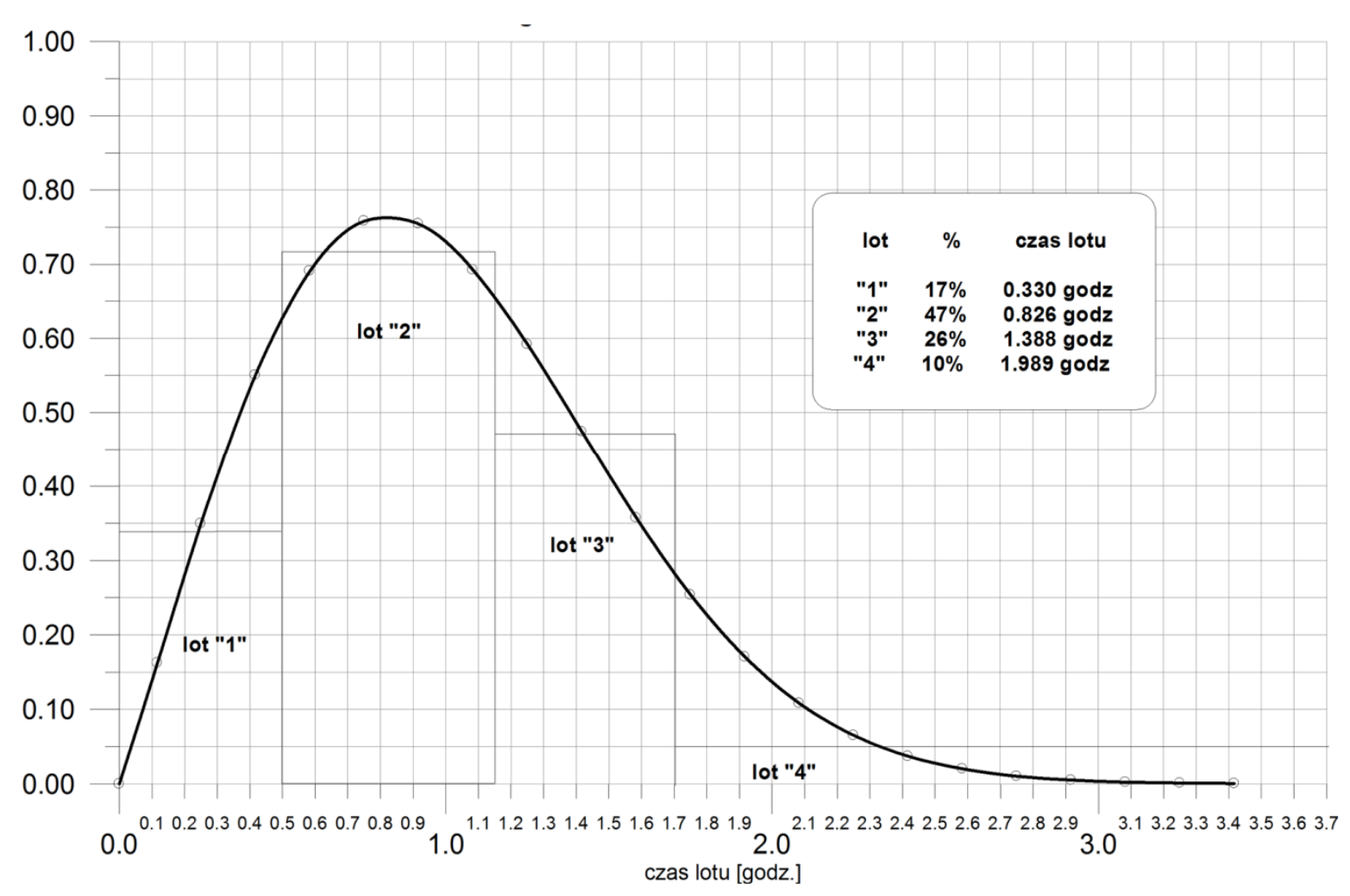

Fig. 2. Distribution of flight duration for sample PZL M28 05 airplane, with Weibull distribution approximation.

The established model of airplane operation significantly affects fatigue damage of the empennage. In consequence, its fatigue test loads spectrum depends on the ground loads on unpaved airstrip. Ground loads also contribute to fatigue damage of the wing and wing loads carry-through structure though not so significantly as in the case of the empennage. Hence, the fatigue test load spectrum is dominated by flight loads resulted from maneuvers and gusts.

\section{SELECTION OF LOADS TO FATIGUE TEST}

Typical flight load spectra resulting from maneuvers and gusts as well as ground loads spectra resulting from taxiing and landing were determined according to the FAA advisory circular AC23-13A [3], and were validated by measurements during test flights. As a result, continuous load spectra were established. For the fatigue tests purposes, these spectra had to be replaced with several load levels, with adequate number of cycles. The fatigue test economy requires that the number of cycles should be as low as possible, bearing in mind test accuracy - see AC-23-13A.

The selection of load levels and number of cycles requires certain levels are rejected keeping a proper proportion between fatigue damage resulting from load cycles occurring at least once a flight and those which are not present at each flight. Figure 3 shows fatigue damage of the wing structure as function of positive load factor increase [2]. It can be seen that the biggest fatigue damage is for the $\mathrm{n}_{\mathrm{z}}$ increase of $0,35 \mathrm{~g}$, which occurs in each flight. 32,6\% of total fatigue damage results from cycles occurring less frequently than once a flight, while $67,4 \%$ results from cycles occurring in each flight. This indicates that loads occurring less frequently than in each flight should be also taken into account. 


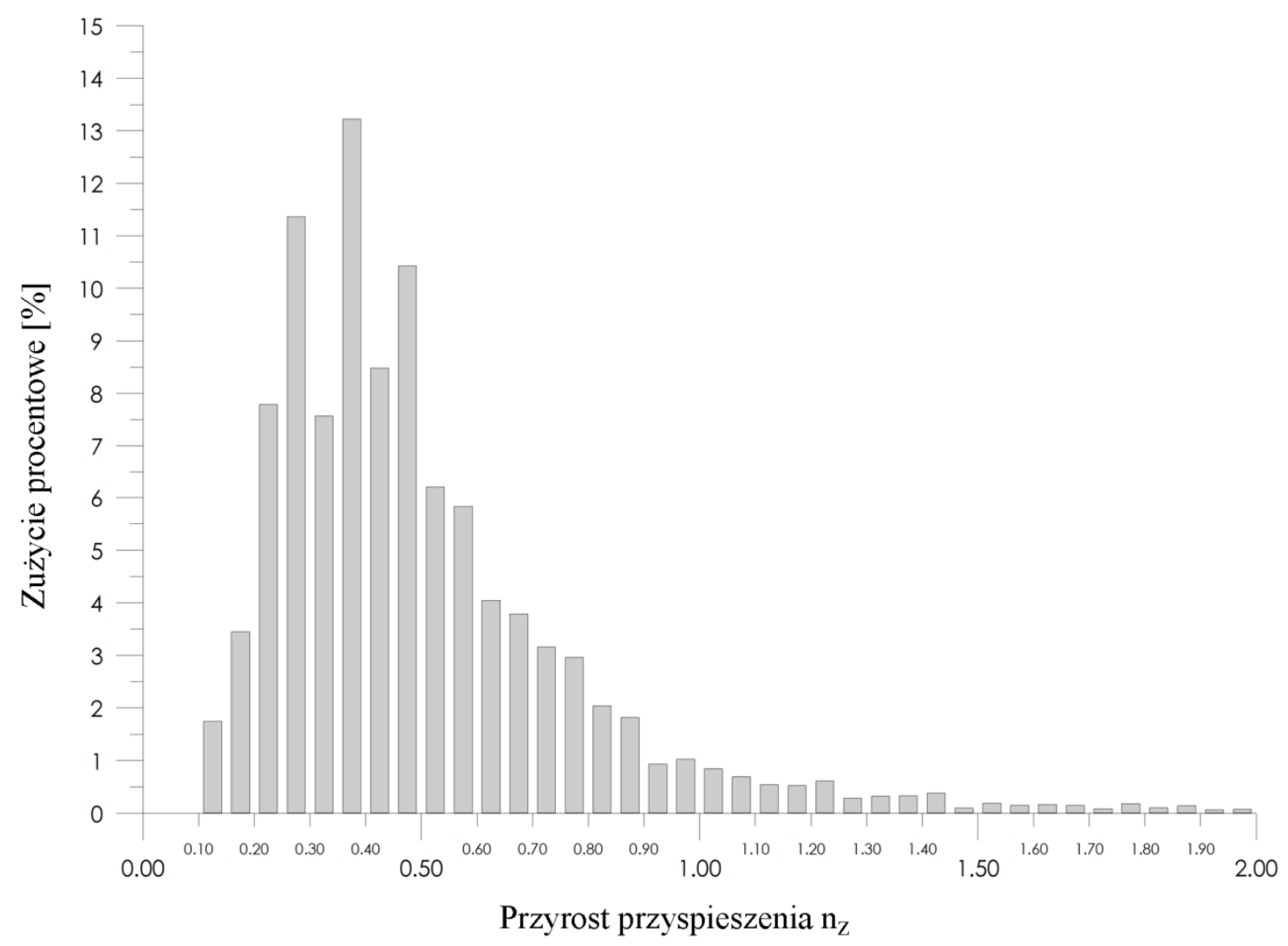

Fig. 3. Percentage of total fatigue damage resulted from a particular load level expressed as load factor $\left(n_{z}\right)$ increase.

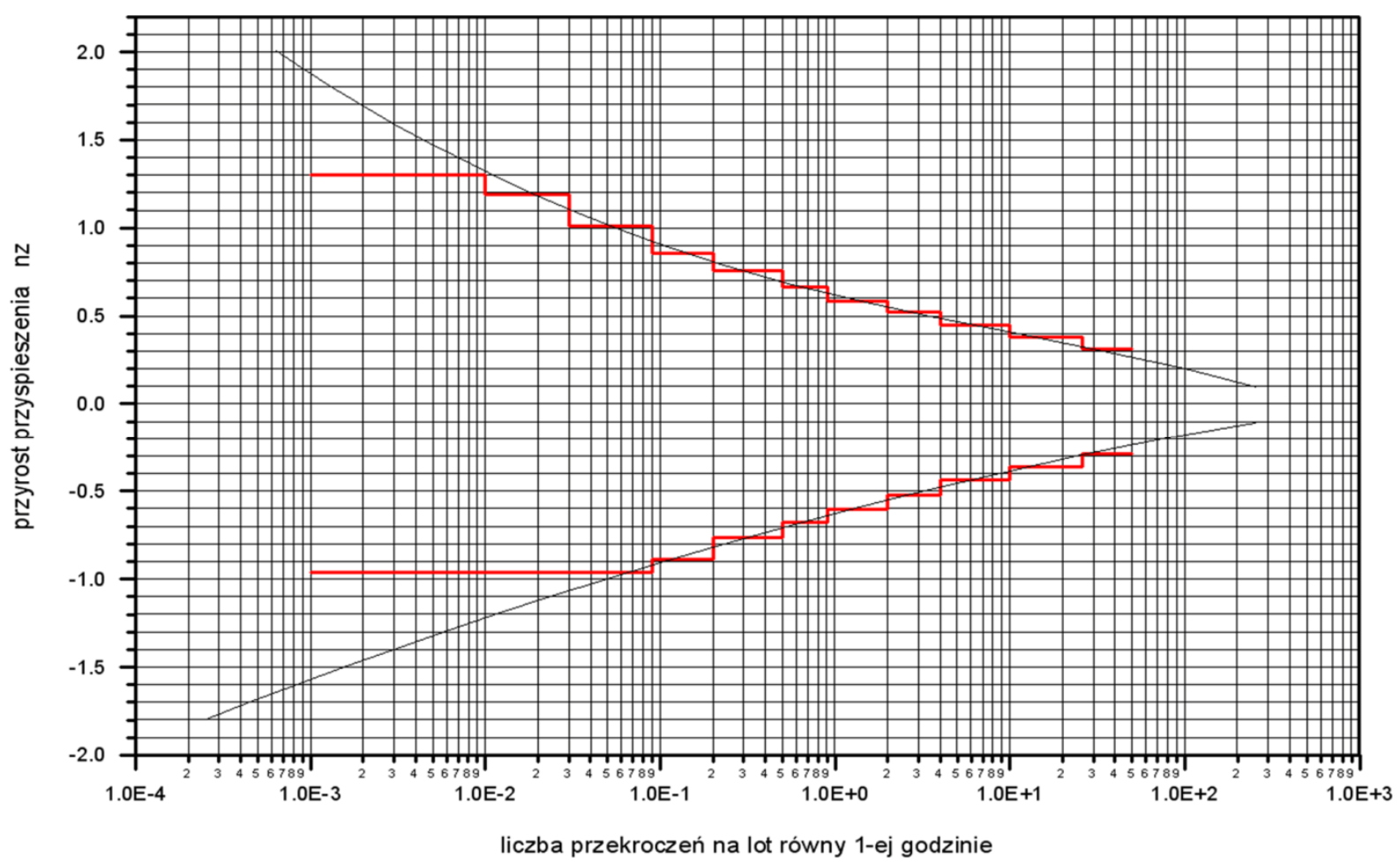

Fig. 4. Discretised load spectrum applied in fatigue test (red line).

Base continuous load spectrum is also shown. 
According to the fatigue analysis about $25 \%$ of wing fatigue damage is GAG result. So, in the fatigue tests of wing and wing loads carry-through structure the ground loads are also taken into account. The selection of load levels for fatigue tests was done by iteration for different load levels sets while preserving the basic assumptions. The final result was 11 load levels with loads occurring at 100 flights considered as shown in Fig. 4 [2]. Of course, total fatigue damage for test load spectrum is the same as for the continuous load spectrum.

\section{WING LOADS DISTRIBUTION IN FATIGUE TEST}

Wing loads are applied spanwise at 16 wing stations [2], 5 on each outer wing and 6 on centerwing in order to represent the wing bending moment, shear force and torque moment distribution. LH stations and RH stations are located symmetrically. Because of high aspect ratio, loads are introduced through clamps. By selection of clamps location and load distribution at clamps it was possible to simulate the wing loads distribution with adequate accuracy - see Fig. 5 .

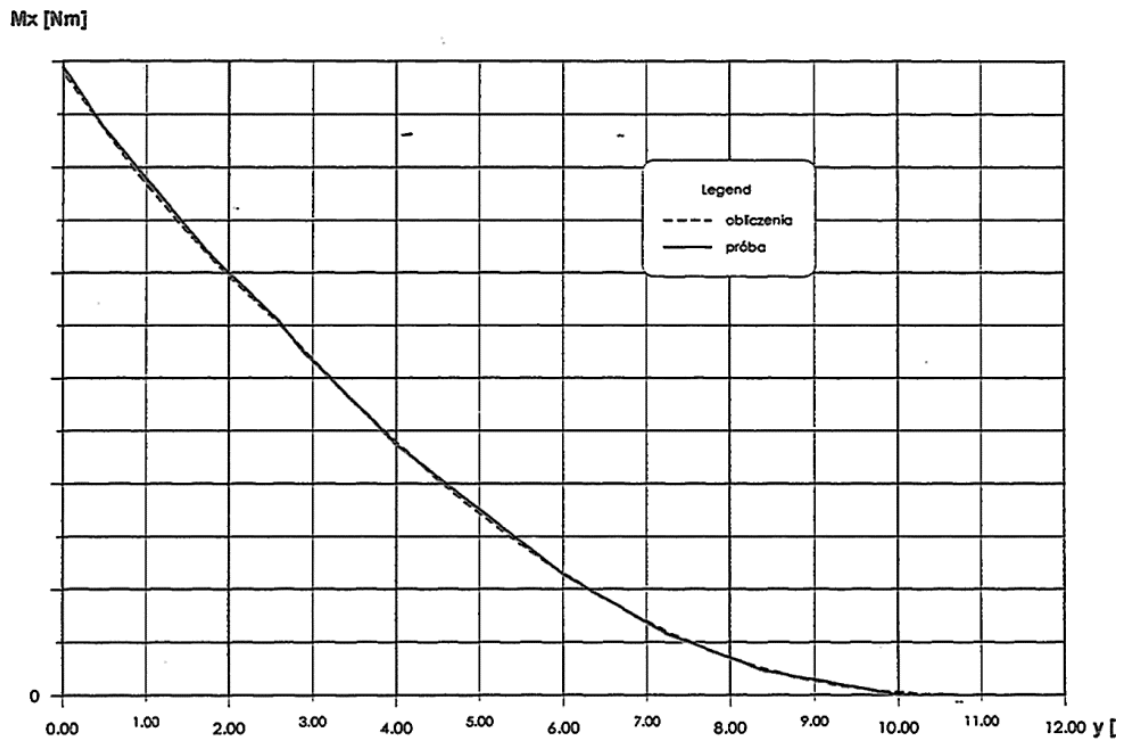

Fig. 5 (a). Wing bending moment spanwise distribution at a level flight: according to loads analysis (dashed line), and applied in fatigue test (continuous line). Note: wing strut effect is not taken into account. 


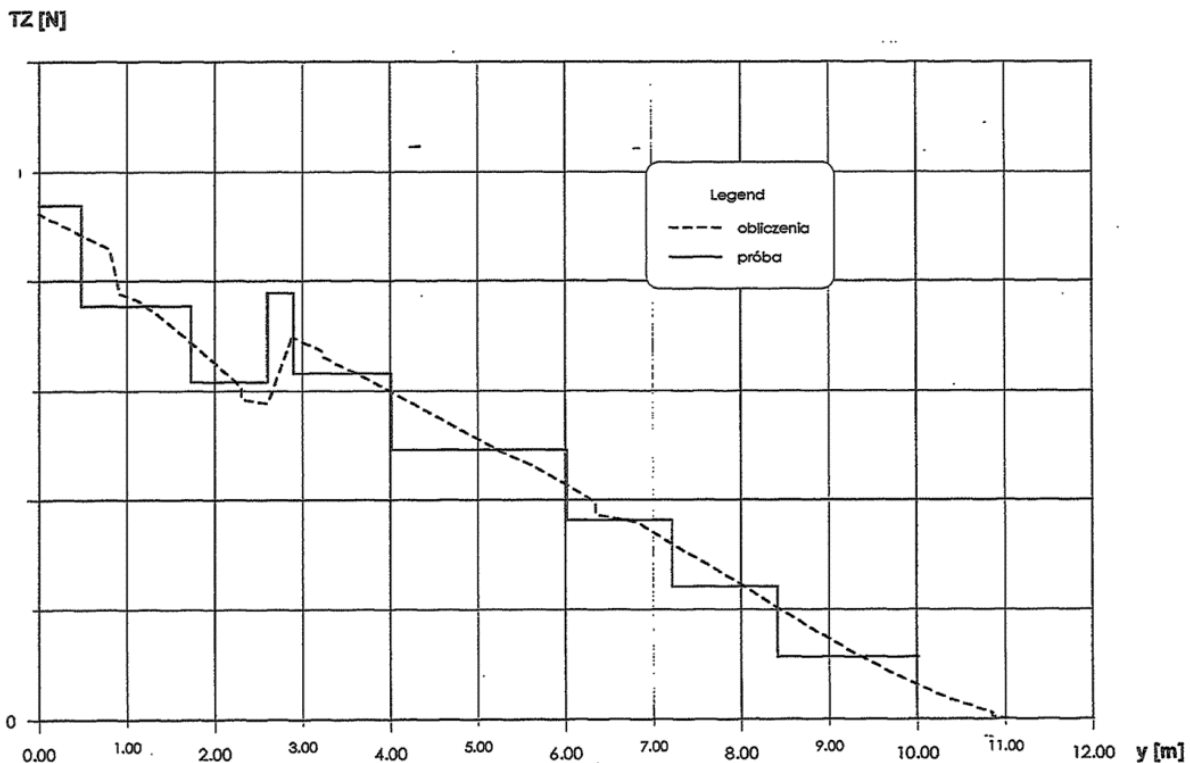

Fig. 5 (b). Wing shear force spanwise distribution at a level flight: according to loads analysis (dashed line), and applied in fatigue test (continuous line). Note: wing strut effect is not taken into account.

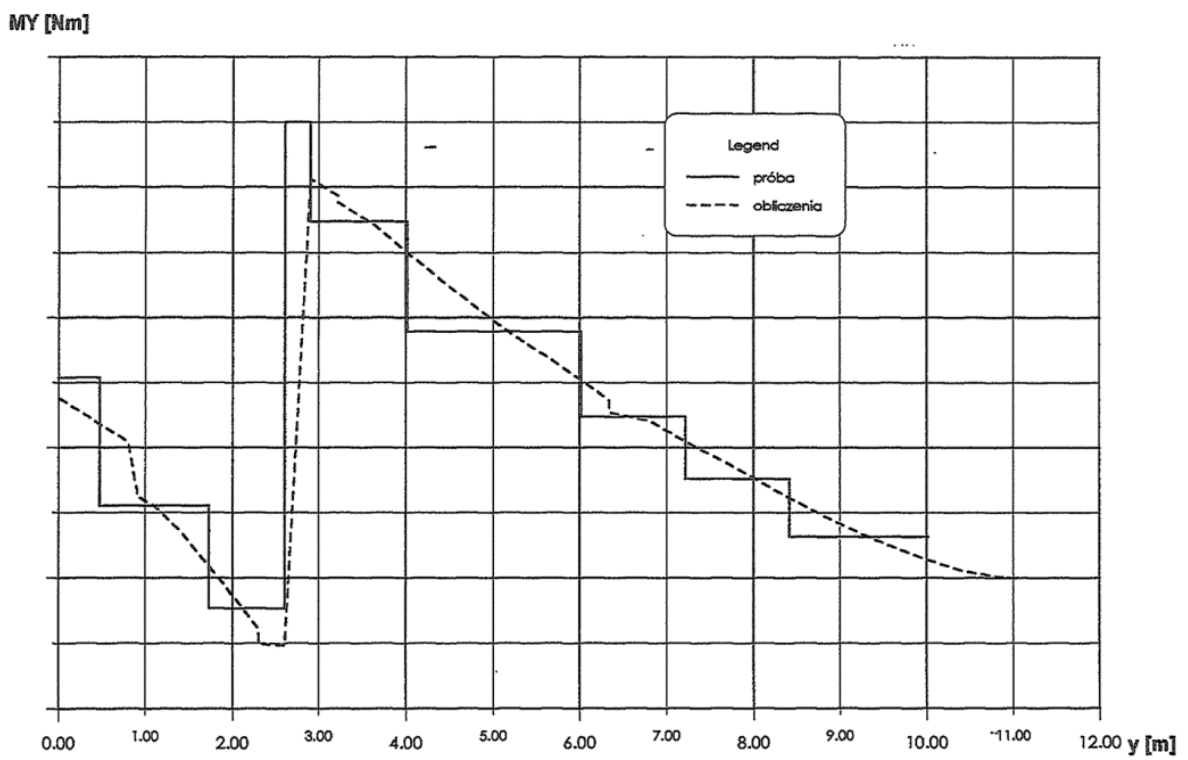

Fig. 5 (c). Wing torque moment spanwise distribution at a level flight: according to loads analysis (dashed line), and applied in fatigue test (continuous line). Note: wing strut effect is not taken into account.

\section{FINAL REMARKS}

The fatigue test plan of the wing and wing load carry-through structure of the PZL M28 05 was conducted without any significant modifications. The test plan enabled performing 100 flights within approximately 8 hours, which was deemed satisfactory from the required time consumption point of view, i.e. the economy of test. 


\section{REFERENCES}

1. J. Pietruszka "Full-Scale Fatigue Tests of PZL M28 05 SKYTRUCK Aircraft". Transactions of Institute of Aviation, 1/2009 (196). Warszawa, 2009.

2. L. Pieróg "Evaluation of PZL M28 05 Airplane Service Life". Ref. no.: DRG/O/W/24/11. PZL internal report. Mielec, 2011.

3. "Fatigue, Fail-Safe, and Damage Tolerance Evaluation of Metallic Structure for Normal, Utility, Acrobatic, and Commuter Category Airplanes". AC 23-13A. FAA. September 29, 2005. 